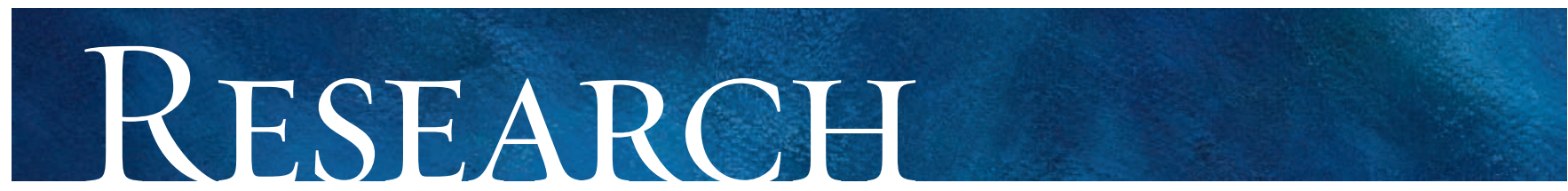

\title{
Residence location and likelihood of kidney transplantation
}

\author{
Marcello Tonelli, Scott Klarenbach, Braden Manns, Bruce Culleton, Brenda Hemmelgarn, \\ Stefania Bertazzon, Natasha Wiebe, John S. Gill, for the Alberta Kidney Disease Network
}

$\infty \quad$ See related article page 489

\section{ABSTRACT}

Background: In a universal, public health care system, access to kidney transplantation should not be influenced by residence location. We determined the likelihood of kidney transplantation from deceased donors among Canadian dialysis patients living in 7 geographic regions. Within each region we also determined whether distance from the closest transplant centre was associated with the likelihood of transplantation.

Methods: A random sample of 7034 subjects initiating dialysis in Canada between 1996 and 2000 was studied. We used Cox proportional hazards models to examine the relation between residence location and the likelihood of kidney transplantation from deceased donors over a median period of 2.4 years.

Results: There were significant differences in the likelihood of kidney transplantation from deceased donors and predicted waiting times between the different geographic regions. For example, the adjusted relative likelihood of transplantation in Alberta was 3.74 (95\% confidence interval $[\mathrm{Cl}]$ 2.95-4.76) compared with the likelihood in Ontario $(p<$ 0.001 ). These differences persisted after further adjustment for differences in the rate of deceased organ donation. Within regions, patients who resided $50.1-150 \mathrm{~km}, 150.1-$ $300 \mathrm{~km}$ and more than $300 \mathrm{~km}$ from the closest transplant centre had a similar adjusted likelihood of receiving a kidney transplant as those who lived less than $50 \mathrm{~km}$ away.

Interpretation: The adjusted likelihood of undergoing a kidney transplant from a deceased donor varied substantially between geographic regions in Canada. In contrast, the likelihood of transplantation within regions was not affected by distance from the closest transplant centre.

CMAJ 2006; $175(5): 478-82$

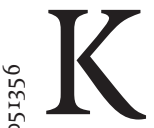

idney transplantation is a life-saving medical procedure for which the demand far exceeds the supply of transplantable organs. Traditionally, access to transplantation is rationed according to the anticipated benefit to individual patients compared with dialysis treatment. ${ }^{1,2}$ This practice is generally accepted because, unlike most other scarce medical resources, access to transplantation cannot be enhanced simply by increased resource allo- cation. In contrast, access to transplantation among suitable candidates should not be influenced by characteristics such as age, sex, race, socioeconomic status or residence location. ${ }^{3}$ Compared with other industrialized nations, Canada is characterized by its large size and relatively few transplant centres, which suggests that access to transplantation may be influenced by geographic considerations.

We studied kidney transplantation from deceased donors as an example of a scarce medical resource that is rationed in Canada's public health care system, focusing on the relation between place of residence and access to transplantation. First, because kidneys are not shared between geographic regions, we hypothesized that there would be regional variations in the likelihood of transplantation. Second, because the mandatory medical evaluation before transplantation is only available in tertiary care centres, ${ }^{4,5}$ we hypothesized that people residing further from the nearest transplant centre would be less likely than those living closer to undergo transplantation .

\section{Methods}

This study was approved by the ethics review board at the University of Alberta and was conducted on a random sample of data from the Canadian Organ Replacement Registry (CORR), ${ }^{6,7}$ which collects patient-specific data annually from all Canadian dialysis centres. Using a 2-step process that ensured the privacy of subjects (see online Appendix I, available at www.cmaj.ca/cgi/content/full/I75/5/478/DCI), we received a randomly selected subject-level dataset from CORR, which included clinical and demographic data, geographic location and distance from transplant centre for 7034 patients (about $36 \%$ of all subjects initiating dialysis in Canada between Jan. I, I996, and Dec. 3I, 2000).

Kidneys from deceased donors are not shared nationally in Canada. Instead organs are shared within 7 regions that closely follow provincial boundaries: British Columbia (includes Yukon Territory), Alberta (includes Northwest Territories), Saskatchewan, Manitoba, Ontario, Quebec and Atlantic Canada (New Brunswick, Nova Scotia, Prince Edward Island, and Newfoundland and Labrador). Although there may be multiple transplant centres within these regions, organs are almost exclusively allocated within the region where the organs were obtained. For this reason, and because responsibility for delivery of health care is primarily provincial in Cana- 
Table 1: Demographic and clinical characteristics of study participants who initiated dialysis between 1996 and 2000 , by distance from renal transplant centre

\begin{tabular}{|c|c|c|c|c|c|}
\hline \multirow[b]{2}{*}{ Characteristic } & \multicolumn{4}{|c|}{ Distance from transplant centre; \% of patients $(95 \% \mathrm{Cl})^{*}$} & \multirow[b]{2}{*}{$p$ value } \\
\hline & $\begin{array}{l}<50 \mathrm{~km} \\
n=4132\end{array}$ & $\begin{array}{c}50.1-150 \mathrm{~km} \\
n=1198\end{array}$ & $\begin{array}{c}150.1-300 \mathrm{~km} \\
\quad n=700\end{array}$ & $\begin{array}{l}>300 \mathrm{~km} \\
n=1004\end{array}$ & \\
\hline $\begin{array}{l}\text { Age, yr, median no. } \\
\text { (interquartile range) }\end{array}$ & $65(52-74)$ & $65(53-74)$ & $66(53-74)$ & $64(50-73)$ & $0.09 \dagger$ \\
\hline Male & $59(58-61)$ & $60(57-62)$ & $59(56-63)$ & $59(56-62)$ & 0.99 \\
\hline \multicolumn{6}{|l|}{ Race } \\
\hline White & $66(64-67)$ & $79(77-82)$ & $81(77-83)$ & $81(78-83)$ & $<0.001$ \\
\hline Aboriginal & $2(1-2)$ & $4(3-6)$ & $8(6-10)$ & $11(9-13)$ & $<0.001$ \\
\hline Non-Aboriginal, non-white & $18(17-19)$ & $3(2-4)$ & $3(2-5)$ & $1(0-2)$ & $<0.001$ \\
\hline Unknown & $14(13-16)$ & $14(12-16)$ & $8(6-11)$ & $7 \quad(6-9)$ & $<0.001$ \\
\hline \multicolumn{6}{|l|}{$\begin{array}{l}\text { Cause of end-stage renal } \\
\text { disease }\end{array}$} \\
\hline Diabetic nephropathy & $31(29-32)$ & $31(28-33)$ & $34(31-38)$ & $30(27-33)$ & 0.23 \\
\hline Glomerulonephritis & $16(15-17)$ & $14(12-16)$ & $14(11-17)$ & $15(13-17)$ & 0.17 \\
\hline $\begin{array}{l}\text { Hypertensive/ischemic renal } \\
\text { disease }\end{array}$ & $19(18-20)$ & $22(20-24)$ & $20(18-24)$ & $20(17-22)$ & 0.09 \\
\hline Polycystic kidney disease & $5 \quad(4-6)$ & $5 \quad(4-6)$ & $4 \quad(2-5)$ & $4 \quad(3-6)$ & 0.50 \\
\hline Other & $29(28-31)$ & $28(26-31)$ & $28(24-31)$ & $31(28-34)$ & 0.40 \\
\hline \multicolumn{6}{|l|}{ Comorbidity } \\
\hline Diabetes mellitus $\neq$ & $8 \quad(7-9)$ & $10 \quad(8-12)$ & $9 \quad(7-11)$ & $8(6-10)$ & 0.16 \\
\hline Coronary disease§ & $36(34-37)$ & $34(31-37)$ & $38(34-41)$ & $34(31-37)$ & 0.22 \\
\hline Hypertension & $76(75-77)$ & $76(73-78)$ & 76 (73-79) & $75(73-78)$ & 0.96 \\
\hline Chronic heart failure & $30(28-31)$ & $28(26-31)$ & $25(22-29)$ & $25(23-28)$ & 0.01 \\
\hline Stroke or TIA & $11(10-12)$ & $12(10-14)$ & $9 \quad(7-12)$ & $9 \quad(8-11)$ & 0.09 \\
\hline Chronic lung disease & $10(9-11)$ & $11(9-12)$ & $11(9-14)$ & $12(10-15)$ & 0.25 \\
\hline Peripheral vascular disease & $18(16-19)$ & $17(15-19)$ & $21(18-24)$ & $19(17-22)$ & 0.12 \\
\hline Malignant disease & $9 \quad(8-10)$ & $10 \quad(8-12)$ & $10(8-13)$ & $11(9-13)$ & 0.17 \\
\hline Current smoker & $12(11-13)$ & $14(12-16)$ & $14(11-16)$ & $16(14-19)$ & 0.001 \\
\hline $\begin{array}{l}\text { Initial peritoneal dialysis } \\
\text { modality }\end{array}$ & $22(21-24)$ & $23(21-25)$ & $20(17-23)$ & $28(25-31)$ & $<0.001$ \\
\hline $\begin{array}{l}\text { In lowest quintile of } \\
\text { socioeconomic status }\end{array}$ & $25(23-26)$ & $22(19-24)$ & $29(26-33)$ & $25(22-28)$ & 0.01 \\
\hline \multicolumn{6}{|l|}{ Regionๆ } \\
\hline Atlantic & $2(2-3)$ & $5 \quad(4-6)$ & $23(20-26)$ & $36(33-39)$ & $<0.001$ \\
\hline Quebec & $26(25-28)$ & $21(18-23)$ & $23(20-26)$ & $7 \quad(6-9)$ & $<0.001$ \\
\hline Ontario & $45(43-46)$ & $53(50-56)$ & $18(15-21)$ & $23(20-25)$ & $<0.001$ \\
\hline Manitoba & $5 \quad(5-6)$ & $3(2-4)$ & $7 \quad(5-9)$ & $3(2-4)$ & $<0.001$ \\
\hline Saskatchewan & $1(1-1)$ & $3(2-4)$ & $16(13-19)$ & $5 \quad(3-6)$ & $<0.001$ \\
\hline Alberta & $8 \quad(8-9)$ & $7 \quad(5-8)$ & $10 \quad(7-12)$ & $3(2-5)$ & $<0.001$ \\
\hline British Columbia & $11(11-13)$ & $9 \quad(7-10)$ & $3(2-5)$ & $23(20-25)$ & $<0.001$ \\
\hline $\begin{array}{l}\text { Residents per generalist, } \\
\text { median no. (IQR) }\end{array}$ & 912 (697-1256) & 1527 (1103-2291) & 1239 (810-1837) & $1058(621-1213)$ & $<0.001 \dagger$ \\
\hline $\begin{array}{l}\text { Residents per specialist, } \\
\text { median no. (IQR) }\end{array}$ & $668(400-1609)$ & $2111(1210-4681)$ & 1391 (963-4335) & $1082(803-1663)$ & $<0.001 \dagger$ \\
\hline
\end{tabular}

Note: $\mathrm{Cl}=$ confidence interval, $\mathrm{TIA}=$ transient ischemic attack, IQR = interquartile range.

*Unless stated otherwise.

†Kruskal-Wallis test.

fln patients for whom the primary cause of end-stage renal disease was not diabetic nephropathy.

§lncludes angina, prior myocardial infarction or prior coronary revascularization.

ๆAtlantic Canada = New Brunswick, Nova Scotia, Prince Edward Island, and Newfoundland and Labrador; "Alberta” includes the Northwest Territories;

"British Columbia" includes the Yukon Territory. 
da, we classified geographic location on the basis of these 7 regions rather than at the level of individual transplant centres. The rate of organ donation from deceased donors varies between regions. Within regions, organs are allocated to wait-listed adult patients according to a number of factors, including $\mathrm{ABO}$ blood group compatibility, human leukocyte antigen (HLA) compatibility, HLA matching, waiting time and, in rare cases, medical urgency.

The Canadian Census reports data in geographic units such as census consolidated subdivisions (CCS), which constitute municipalities or their deemed equivalents. Because socioeconomic attributes of areas in which people reside may influence their access to health care, ${ }^{8}$ we assessed these characteristics for each CCS.

For the statistical analysis, the primary outcome was time to kidney transplantation from a deceased donor. Patients were followed from initiation of dialysis until death, transplantation, loss to follow-up or end of study (Dec. 3I, 2002). Because the focus of this study was on kidney transplantation from deceased donors, we censored follow-up at the time of transplantation from a living donor. The effects of geographic region and residence location (distance from residence to nearest transplant centre) were explored. The distance from each patient's residence to the transplant centre was arbitrarily categorized a priori as follows: less than $50 \mathrm{~km}, 50 . \mathrm{I}-150 \mathrm{~km}$, I50.I-300 km and more than $300 \mathrm{~km}$. Patients living in remote communities for which no consistent access by road was available were assigned to the last category.

Details of the statistical methods used to perform the analyses appear in online Appendix I (available at www.cmaj .ca/cgi/content/full/175/5/478/DCI). The adjusted association between residence location and time to transplantation was determined using a Cox proportional hazards model. We adjusted for demographic and clinical characteristics as well as for the annual rate of kidney donation from deceased donors in each region. We performed a variety of sensitivity analyses to ensure that our findings were robust, including using an alternative distance classification based on 6 categories, restricting analyses to subjects who were likely to be acceptable transplant candidates on the basis of their lower age and lack of comorbid conditions, and considering transplants from living donors only. Using logistic regression analysis, we estimated the predicted proportion of patients receiving a kidney from a deceased donor in the first 3 years following initiation of dialysis. We also estimated the predicted median time to transplantation in certain patient groups (i.e., the time until $50 \%$ of all patients received a transplant) using a parametric model.

\section{Results}

Over the median follow-up of 2.4 years, $10.6 \%$ of the patients who initiated dialysis between 1996 and 2000 received a kidney transplant from a deceased donor; of the remainder, $5.8 \%$ received a transplant from a living donor, $46.0 \%$ died, and $0.5 \%$ were lost to follow-up. Of the 7034 participants, $4 \mathrm{I} 32(58.7 \%)$ lived within $50 \mathrm{~km}$ of the closest transplant centre at dialysis inception, as compared with 10.0\% who lived I50.I-300 km away and I4.3\% who lived more than 300 $\mathrm{km}$ from the closest centre (Table I). Patients who lived further away were more likely than those who lived closer to the transplant centre to initiate renal replacement on peritoneal dialysis and to smoke. The marker of neighbourhood socioeconomic status and the supply of primary care physicians were similar among patients residing closest to and furthest from renal transplant centres, although both were lower among patients at intermediate distances. There were no consistent trends in baseline comorbidity by residence location (Table I).

We found significant differences in the adjusted relative likelihood of kidney transplantation when patients residing in different geographic regions were compared (Table 2).

Table 2: Likelihood (hazard ratio) of kidney transplantation from deceased donor, by geographic region

Adjusted hazard ratio $(95 \% \mathrm{Cl})$

\begin{tabular}{llcc} 
& \multicolumn{2}{c}{ Adjusted hazard ratio $(95 \% \mathrm{Cl})$} & \\
\cline { 2 - 3 } Geographic region & Transplantation & $\begin{array}{c}\text { Transplantation based } \\
\text { on annual donor rate } \\
\text { per million population }\end{array}$ & $\begin{array}{c}\text { Rate of } \\
\text { transplantation } \\
\text { per } 100 \text { patient-years }\end{array}$ \\
\hline Atlantic Canada† & $2.17(1.60-2.93)$ & $2.38(1.72-3.30)$ & $4.9(4.0-6.1)$ \\
\hline Quebec & $1.96(1.60-2.39)$ & $1.71(1.30-2.26)$ & $5.7(5.0-6.5)$ \\
\hline Ontario & $1.00 \ddagger$ & $1.00 \ddagger$ & $2.6(2.3-3.0)$ \\
Manitoba & $0.95(0.61-1.50)$ & $0.97(0.62-1.53)$ & $2.4(1.6-3.7)$ \\
\hline Saskatchewan & $2.63(1.75-3.95)$ & $2.39(1.56-3.67)$ & $5.9(4.1-8.4)$ \\
\hline Alberta & $3.74(2.95-4.76)$ & $3.19(2.31-4.40)$ & $8.9(7.4-10.7)$ \\
\hline British Columbia & $1.05(0.79-1.38)$ & $0.93(0.66-1.30)$ & $3.3(2.6-4.2)$ \\
\hline
\end{tabular}

Note: $\mathrm{Cl}=$ confidence interval.

*Adjusted for age, sex, race, primary cause of end-stage renal disease, year of diagnosis, comorbidities (diabetes mellitus, coronary disease, congestive heart failure, stroke or transient ischemic attack, chronic lung disease, other serious medical illness, peripheral vascular disease, malignant disease), smoking status, initial dialysis modality, socioeconomic status and distance from transplant centre.

†Atlantic Canada $=$ New Brunswick, Nova Scotia, Prince Edward Island, and Newfoundland and Labrador.

†Reference category. 
Compared with patients living in Ontario, those in Atlantic Canada, Quebec, Saskatchewan and Alberta were significantly more likely to receive a kidney transplant. For the 4 provinces in Atlantic Canada, the fully adjusted likelihood (hazard ratio) was 2.38 (95\% confidence interval [CI] I.493.79) in Newfoundland and Labrador, 2.53 (95\% CI I.673.85) in Nova Scotia, 2.17 (95\% CI 0.52-9.07) in Prince Edward Island and I.67 (95\% CI I.05-2.6I) in New Brunswick (all compared with Ontario).

These relative likelihoods translated into substantial differences in the proportion of patients in each region who received a kidney from a deceased donor within 3 years after starting dialysis. For example, the median predicted waiting time for a nondiabetic patient less than 40 years of age was 3.I years in Alberta, 7.8 years in British Columbia and 8.0 years in Ontario $(p<0.00 I)$. Results were similar among diabetic patients (data not shown).

In adjusted analyses, patients who resided $50.1-150 \mathrm{~km}$, $150.1-300 \mathrm{~km}$ and more than $300 \mathrm{~km}$ from the closest transplant centre had a similar likelihood of receiving a kidney from a deceased donor as those who lived less than $50 \mathrm{~km}$ away (Table 3). To assess the possibility that distance from the transplant centre was more influential in certain regions than in others, we tested the association of distance on the likelihood of receiving a transplant within each geographic region. In these analyses, subjects who resided further from the transplant centre did not have a significantly reduced likelihood of transplantation in any of the 7 regions (all $p>0 . \mathrm{I}$ ).

Our results did not change when we repeated the analyses after classifying distance from the transplant centre into 6 categories rather than 4 , considering distance as a continuous (rather than categorical) variable, assuming follow-up until end of study for subjects who died without a transplant or restricting analyses to younger patients without comorbid conditions. Including transplants from living donors did not influence our results either. Specifically, increasing distance from the transplant centre was not associated with a reduced likelihood of kidney transplantation from a deceased donor, whereas regional disparities remained.

\section{Interpretation}

We found striking regional differences in the rates of kidney transplantation from deceased donors in Canada. For example, patients residing in Alberta were more than 3 times as likely as those in Ontario to undergo transplantation. In contrast, despite the relatively large catchment areas served by Canadian transplant centres, access to kidney transplantation from deceased donors was similar for remote- and urbandwelling patients, which suggests that additional centres may not be necessary to promote equitable waiting times. Even in Atlantic Canada, where a single centre in Nova Scotia provides care to 4 provinces, there was no evidence of improved access to transplantation among the people who lived closer to the transplant centre.

In theory, the regional differences in transplantation may have been due to differences in supply (number of available organs) or demand (number of potential recipients), or both. Because disparities between regions were attenuated but not eliminated after adjustment for differences in rates of kidney donation from deceased donors, this suggests that both factors are responsible. ${ }^{9}$ Therefore, potential solutions might include organ sharing between provinces, purchase of kidneys from deceased donors in other (non-Canadian) jurisdictions and increasing kidney donation rates. Although increased organ sharing between regions would tend to reduce disparities, the logistical challenges associated with such a system may lead to poor allograft survival owing to prolonged ischemic time. ${ }^{10}$ Balancing the potentially competing interests of equity and population health will require careful consideration of the alternatives by key stakeholders, including nephrologists, transplant surgeons, decision-makers, patients and the public. In the meantime, efforts to increase both deceased and living kidney donation should continue, since this objective would be desirable even in the absence of regional disparities.

Regional differences in kidney transplantation rates have been previously described in other countries, including the United States. ${ }^{11,12}$ However, unlike American legislation, the Canada Health Act mandates reasonable and uniform access

Table 3: Likelihood of kidney transplantation from deceased donor, by distance from closest transplant centre

Adjusted hazard ratio $(95 \% \mathrm{Cl})^{*}$

\begin{tabular}{lccc}
\cline { 2 - 3 } $\begin{array}{l}\text { Distance from } \\
\text { transplant centre, } \mathrm{km}\end{array}$ & Transplantation only & $\begin{array}{c}\text { Transplantation based } \\
\text { on annual donor rate } \\
\text { per million population }\end{array}$ & $\begin{array}{c}\text { Rate of } \\
\text { transplantation } \\
\text { per } 100 \text { patient-years }\end{array}$ \\
\hline$<50$ & $1.00 \dagger$ & $1.00 \dagger$ & $3.9(3.6-4.3)$ \\
$50.1-150$ & $1.11(0.90-1.36)$ & $1.11(0.91-1.37)$ & $4.3(3.7-5.2)$ \\
$150.1-300$ & $0.76(0.58-1.01)$ & $0.76(0.58-1.01)$ & $3.9(3.0-4.9)$ \\
$>300$ & $0.96(0.75-1.23)$ & $0.96(0.74-1.23)$ & $4.9(4.1-5.9)$ \\
\hline
\end{tabular}

Note: $\mathrm{Cl}=$ confidence interval.

*Adjusted for age, sex, race, primary cause of end-stage renal disease, year of diagnosis, comorbid conditions (diabetes mellitus, coronary disease, congestive heart failure, stroke or transient ischemic attack, chronic lung disease, other serious medical illness, peripheral vascular disease, malignant disease), smoking status, initial dialysis modality, socioeconomic status and geographic region.

†Reference category 
to medically necessary services for all Canadians, and the differences we noted between provinces may not meet this criterion. Because the cumulative likelihood of death while awaiting a kidney transplant increases with time,${ }^{13}$ the longer waiting times may adversely affect survival in certain regions, although this remains speculative. Our findings are similar to those from a Scottish study that found no statistical difference in the likelihood of transplantation between patients residing more than and those resideng less than $100 \mathrm{~km}$ from the closest transplant centre, ${ }^{14}$ although distances were generally much smaller than those in our analysis.

Limitations of our study include our classification of residence location at the time of dialysis inception. Because some participants may have moved after starting dialysis but before transplantation, the resulting misclassification may have introduced bias. Second, although previously validated, the methods we used to calculate distances necessitated some approximations. We attempted to reduce the risk of misclassification by categorizing distances from transplant centres into relatively broad categories. Third, although we did not have information on transplant eligibility, our results were unchanged when we included only participants who were likely to be acceptable transplant candidates in the analysis. Although people living in remote areas may be healthier for a given level of documented comorbidity than apparently comparable urban-dwellers, it seems unlikely that such confounding could account for the substantial differences between regions. Fourth, we did not include transplants occurring before initiation of dialysis in our analyses. However, because these transplants occur almost exclusively from living donors, this exclusion is unlikely to have influenced our results. Fifth, although we attempted to adjust for differences in kidney donation rates between regions, our analysis may still underestimate the contribution of differences in organ supply to the regional disparities..$^{15}$ Finally, our study was based on registry data, which has well-known limitations despite its potential advantages.

In summary, the likelihood of kidney transplantation from deceased donors varied substantially between geographic regions in Canada, apparently because of differences in both supply and demand. Because access to medical services in a public health care system should not be influenced by residence location, this issue deserves further scrutiny. In contrast, the likelihood of transplantation within each region was not affected by distance from the closest transplant centre, which suggests that equitable access to scarce medical resources for people living in remote areas is feasible even in large geographic areas.

This article has been peer reviewed.

From the Division of Nephrology and Transplant Immunology (Tonelli, Klarenbach, Wiebe) and the Division of Critical Care Medicine (Tonelli, Klarenbach), Department of Medicine, and the Department of Public Health Sciences (Tonelli), University of Alberta, Edmonton, Alta.; the Institute of Health Economics (Tonelli, Klarenbach, Manns), Edmonton, Alta.; the Department of Community Health Sciences (Manns, Hemmelgarn), the Divi- sion of Nephrology, Department of Medicine (Manns, Culleton, Hemmelgarn), and the Department of Geography (Bertazzon), University of Calgary, Calgary, Alta.; and the Division of Nephrology (Gill), St. Paul's Hospital, Vancouver, BC, and Tufts-New England Medical Center, Boston, Mass.

Competing interests: None declared.

Contributors: Marcello Tonelli conceived the study concept. The detailed analysis plan was devised by Marcello Tonelli, Natasha Wiebe and John Gill, with input from the other coauthors. MarcelloTonelli wrote the article, with input from John Gill, Brenda Hemmelgarn and Natasha Wiebe. All of the authors helped to obtain funding, revised the manuscript for important intellectual content, assisted with further revisions following peer review and approved the final manuscript to be published.

Acknowledgements: We thank Andy K.J. Kim, Frank Ivis and Kim Badovinac from the Canadian Organ Replacement Register for their assistance.

Marcello Tonelli and Brenda Hemmelgarn were supported by Population Health Investigator Awards from Alberta Heritage Foundation for Medical Research. They, along with Braden Manns, were supported by New Investigator Awards from the Canadian Institutes for Health Research. John Gill was supported by the Michael Smith Foundation for Medical Research. This study was supported by the Alberta Kidney Disease Network and by operating grants from the Canadian Institutes for Health Research and the University of Alberta Hospital Foundation.

\section{REFERENCES}

I. Wolfe RA, Ashby VB, Milford EL, et al. Comparison of mortality in all patients on dialysis, patients on dialysis awaiting transplantation, and recipients of a first cadaveric transplant. N Engl J Med I999;34I:1725-30.

2. Loubeau PR, Loubeau JM, Jantzen R. The economics of kidney transplantation versus hemodialysis. Prog Transplant 200I;II:29I-7.

3. Commission on the Future of Health Care in Canada (Romanow RJ, Commissioner). Building on values: the future of health care in Canada. Final report. Ottawa: The Commission; 2002. Cat no $\mathrm{CP}_{32}-85 / 2002 \mathrm{E}-\mathrm{IN}$. Available: www.cbc.ca /healthcare/final_report.pdf (accessed 2006 June 6).

4. Holley JL, Monaghan J, Byer B, et al. An examination of the renal transplant evaluation process focusing on cost and the reasons for patient exclusion. Am J Kidney Dis $1998 ; 32: 567-74$.

5. Gallon LG, Leventhal JR, Kaufman DB. Pretransplant evaluation of renal transplant candidates. Semin Nephrol 2002;22:515-25.

6. Canadian Institute for Health Information (CIHI). Canadian Organ Replacement Register 2001 report. Volume I: Dialysis and renal transplantation (includes data I98I-I999). Ottawa: CIHI; Aug 200I. Available: http://ecomm.cihi.ca/ec/product .asp?dep_id=I5\&sku=oICORRVOLIPDF (accessed 2006 July 24).

7. Schaubel DE, Stewart DE, Morrison HI, et al. Sex inequality in kidney transplantation rates. Arch Intern Med 2000;160:2349-54.

8. James P, Wysong JA, Rosenthal T, et al. Access to care in regionalized health care systems. JAMA I996;275:758-9.

9. Canadian Institute for Health Information (CIHI). Estimating potential cadaveric organ donors for Canada and its provinces, I992 to 1998. Ottawa: CIHI; 200I. Available: www.cihi.ca/cihiweb/en/downloads/reports_cadavericdonors_e_Pot Cadaveric.pdf (accessed 2006 June 6).

Io. Salahudeen AK, Haider N, May W. Cold ischemia and the reduced long-term survival of cadaveric renal allografts. Kidney Int 2004;65:713-8.

II. Ellison MD, Edwards LB, Edwards EB, et al. Geographic differences in access to transplantation in the United States. Transplantation 2003;76:1389-94.

I2. Roudot-Thoraval F, Romano P, Spaak F, et al. Geographic disparities in access to organ transplant in France. Transplantation 2003;76:1385-8.

13. Okechukwu CN, Lopes AA, Stack AG, et al. Impact of years of dialysis therapy on mortality risk and the characteristics of longer term dialysis survivors. Am J Kidney Dis 2002;39:533-8.

I4. Oniscu GC, Schalkwijk AA, Johnson RJ, et al. Equity of access to renal transplant waiting list and renal transplantation in Scotland: cohort study. BMJ 2003;327:I26I.

15. Sheehy E, Conrad SL, Brigham LE, et al. Estimating the number of potential organ donors in the United States. NEngl J Med 2003;349:667-74.

Correspondence to: Dr. Marcello Tonelli, Division of Nephrology and Transplant Immunology, University of Alberta, 7-I29 Clinical Sciences Building, 8440-II2 St., Edmonton AB T6B 2B7;

fax 780 407-7878; mtonelli@ualberta.ca 